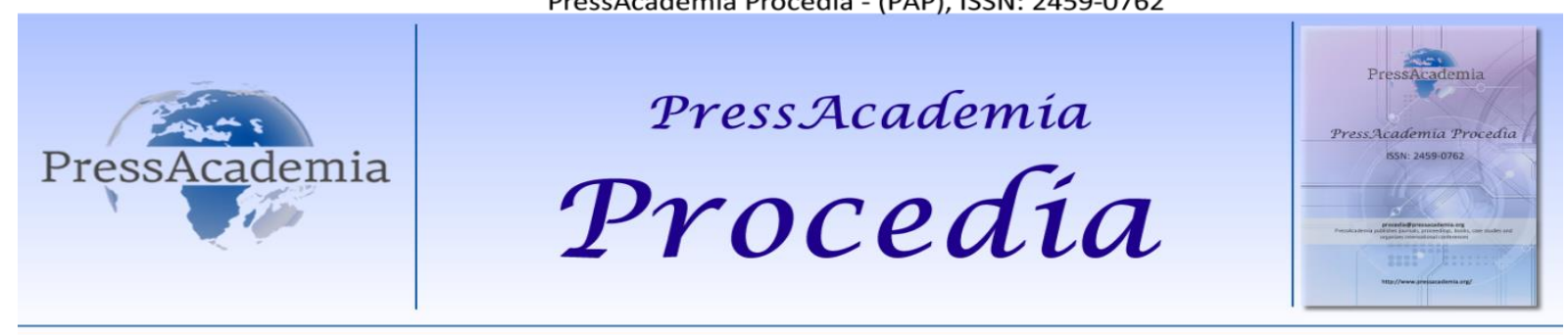

Global Business Research Congress (GBRC), May 24-25, 2017, Istanbul, Turkey

\title{
MOBBING IN HEALTHCARE INSTITUTIONS: IS IT AN OBSTACLE TO ENTREPRENEURSHIP?
}

\author{
DOI: 10.17261/Pressacademia.2017.654 \\ PAP- GBRC-V.3-2017(80)-p.755-758
}

Gulseren Keskin ${ }^{1}$, Gul Ozlem Yildirim² ${ }^{2}$ Elif Aktekin ${ }^{3}$, Sureyya Gumussoy ${ }^{4}$

${ }^{1}$ Ege University Atatürk Health Care Vocational School, Bornova/izmir, Türkiye. gulseren.keskin@ege.edu.tr

${ }^{2}$ Ege University Atatürk Health Care Vocational School, Bornova/Izmir, Türkiye. gulozlemy@yahoo.com

${ }^{3}$ Ege University Atatürk Health Care Vocational School, Bornova/izmir, Türkiye. elif_aktekin@hotmail.com

${ }^{4}$ Ege University Atatürk Health Care Vocational School, Bornova/izmir, Türkiye. sureyya.gumussoy@ege.edu.tr

\section{To cite this document}

Keskin G, G. O. Yildirim, E. Aktekin, S. Gumussoy (2017). Mobbing in healthcare institutions: is it an obstacle to entrepreneurship? PressAcademia Procedia (PAP), V.3, p.755-758.

Permemant link to this document: $\underline{\text { http://doi.org/10.17261/Pressacademia.2017.654 }}$

Copyright: Published by PressAcademia and limited licenced re-use rights only.

\begin{abstract}
Entrepreneurship is a concept with an increasing emphasis on the health sector. Mobbing is the most important formation that affects the motivation of health personnel in the negative direction. In this study, it is aimed to examine the effect of the mobing in the workplace on the entrepreneurship activities of the individual. Articles on entrepreneurship are searched by key words such as mobbing, entrepreneurship, in PubMed, Medline, EBSCOHost, PsycINFO, Turkish Medline, Çukurova Index Databases and Google Scholar and it has benefited from the work that is appropriate for review. Today, as in other fields, mobbing is also mentioned in the field of health and there is serious loss of workplace performance in health personnel exposed to mobinge. Individuals can have more devastating consequences than other types of stress. However, systematic violence within an institution may cause an individual to live anxiety, threat, insecurity about the future. This may jeopardize the entrepreneurship of the individual as it can affect the decision-making power, autonomy, in business life. In health institutions, administratively, initiatives to prevent mobiling can help to support the entrepreneurial traits of the staff and improve their performance.
\end{abstract}

Keywords: Entrepreneurship, mobbing, healthcare personnel, entrepreneurship traits, health management JEL Codes: 112, I31, I14, M12

\section{SAĞLIK KURUMLARINDA MOBiNG: GIRIŞiMCILIK IÇCiN BİR ENGEL MIDIR?}

\section{ÖZET}

Girişimcilik sağlık sektöründe giderek artan öneme sahip bir kavramdır. Mobing sağlık personelinin motivasyonunu negatif yönde etkileyen en önemli oluşumlardandır. Bu çalışmada iş yerinde uygulanan mobingin, bireyin girişimcilikle ilgili faaliyetlerine etkisinin incelenmesi amaçlanmıştır. Pubmed, Medline, EBSCOHost, PsycINFO, Türk Medline, Çukurova Dizini veri tabanlarında ve Google Akademik'te yer alan girişimcilik, mobing gibi anahtar kelimeler kullanılarak ilgili makaleler taranmış ve gözden geçirme için uygun olan çalışmalardan yararlanılmıştır. Günümüzde diğer alanlarda olduğu gibi sağlık alanında da mobingden söz edilmekte, mobinge maruz bırakılan sağılı personelinde işyeri performansında ciddi kayıp yaşanmaktadır. Bireysel olarak diğer stres türlerine göre daha yıkıcı sonuçlar doğurabilmektedir. Ancak sistematik şekilde yaşanan kurum içerindeki şiddet bireyin gelecekle ilgili kaygı, tehdit, güvensizlik yaşamasına neden olabilir. Bu durum iş yaşantısında karar verme gücünü, otonomisini etkileyebileceğinden bireyin girişimciliğine ket vurabilir. Sağık kurumlarında yönetimsel olarak, mobingin önlenmesine yönelik yapılacak girişimler, personelin girişimcilik özelliklerinin desteklenmesine ve performansının artmasına neden olabilecektir.

Anahtar Kelimeler: Girişimcilik, mobbing, sağlık personeli, girişimcilik özellikleri, sağlik yönetimi JEL Kodları: I12, I31, I14, M12 


\section{GíRiş}

Özellikle sağlık hizmetlerindeki ihtiyaçların ve açıkların neler olduğunu belirlemek ve bunlara yanıt vermek sağlık alanında profesyonelleşme ve bilimsel gelişmelerin güçlü kullanımı ile mümkündür. Sağılı sektörü, sağıı personelinin girişimcilik ve yenilikçilik faaliyetlerini destekleyerek alanda gelişimi sağlar. Ancak sağlık personelinin motivasyonunu engelleyebilecek durumlar sağlık sektörünü sekteye uğratır. Mobing iş yaşamındaki motivasyonu azaltan önemli bir faktördür. Son yıllarda mobing sağlık kurumlarında da etkisini hızlıca ve sinsice göstermeye başlamış; sağlık personeli arasında rekabeti arttırarak çalışanların sinerjisini ve enerejisini kaybetmelerine neden olmuştur (Karakaş ve Okanlı, 2005). Özellikle stresli ve karmaşık olan sağlık kuruluşlarında mobbing seviyeleri ve yöneticilerin tükenmesi bir organizasyonun başarısını etkileyebilecek faktörlerdir. Sağlık bakımında hata kabul edilemezdir, mobinge uğramış bir ekip üyesinin uyguladığı bakım standartlarında ve kalitesinde düşme yaşanır. Mobbing hem sağlık çalışanlarına hem de sağlık kuruluşlarına zararlı olabilir.

\section{LITERATÜR INCELEMESI}

Son yıllarda işyerinde şiddet, sağlık kuruluşlarında sık görülen bir durumdur. Hastane ortamında en yaygın görülen şiddet türü, hastalar ve yakınları tarafından yapılan sözlü ve fiziksel şiddettir. Bununla birlikte, birçok çalışmada sağlık çalışanları kendi meslektaşları tarfından uygulanan şiddete maruz kalmaktadırlar. Sağlık alanı güçlü etik kuralların hâkim olduğu bir alan olmasına rağmen mobing olarak adlandırılan şiddetin bu özel boyutundan kurtulmuş değillerdir. Mobbing duygusal bir saldırıdır. Mobing sıklıkla bireyi saygısız ve ona zarar verecek davranışlar silsilesine maruz bırakır. Bu tür davranışların hedefi olmakla başlayan süreç, alanda çalışan diğer meslektaşlarının da o kişiye karşı provake edilmesi, sürekli örtülü suçlamaların gerçekleştirilmesi sonucunda agresif bir atmosfer yaratılmasıyla devam eder. Birçok kurban, pozisyonlarını kaybetme korkusu nedeniyle mobinge karşı kayıtsız kalır. Bazıları olumsuz davranışlardan oldukça etkilenir ve sağlıklarını kaybeder. Birçok kişi ciddi bir stres içerisine girer (Topa, Moriano 2013, Sepúlveda-Vildósola 2017) . İş yerinde yaşanan stres bireyin fiziksel ve ruhsal iyilik halinin devamlılığını sağlayan (1)yaşamın anlamı, (2)benlik değeri, (3)dünyanın iyi bir yer olduğuna dair üç temel bilişsel süreci etkilediği belirlenmiştir. Bireyin mental sağ|ı̆̆ı için çalıştığı kurumda diğer insanların iyi ve arkadaş canlısı olduğunu bilmeye, iyi şeylerin başlarına gelebileceğine ve başkalarının saygısına layık olduğuna inanmaya ihtiyacı vardır. Mobing sağlık sektöründe de personelin iş gücünü, girişimciliğini ve organizasyonu etkileyen önemli bir sorun alanıdır. Başarılı girişimcilerin iç kontrol odağı yüksek, yüksek benlik saygısına sahip, risk alabilen bireyler olduğu düşünülmektedir. Bir çalışmada kurum içi mobinge maruz kalan sağlık personelinin \%44'ünde posttravmatik stres bozukluğu bulgularına rastlandığı bildirilmiştir (Kehribar ve ark. 2017).

\section{VERI VE YÖNTEM}

Pubmed, Medline, EBSCOHost, PsycINFO, Türk Medline, Çukurova Dizini veri tabanlarında ve Google Akademik, Ulakbim veritabanlarında girişimcilik, mobing gibi anahtar kelimler kullanılarak kapsamlı bir literatür çalışması yapılmıştır. Literatür taraması 2005- 2017 yılları arasındaki yayınların gözden geçirilmesi ile yapılmıştır. Türkçe ve İngilizce dillerinde yazılmış, tam metin makaleler dâhil edilmiştir. Buna göre girişimcilik ve mobingin değerlendirildiği çalışmalar bu derlemeye alınmıştır. Makale seçimi için aramalar ilk aşamada altı veri tabanında yürütülmüş ve ilgili başılılar/özetler incelemeye alınmıştır ( $n=$ 120). Araştırmaların arasında çalışmanın amacına uygun olanlar belirlenmiştir $(n=20)$. Potansiyel çalışmaların tam metinleri elde edildikten sonra dâhil edilme ölçütlerine uygun olan makaleler seçilmiştir.

\section{BULGULAR VE TARTIŞMA}

İşyerinde mobbing, çalışanların bir veya daha fazla meslektaş veya hiyerarşik bir üstün, astları tarafından sistematik olarak taciz edilmesidir ve hem bireysel çalışanlara hem de kuruluşlara ciddi bir sorun oluşturur (Branch, Ramsay, \& Barker, 2013). Mobing sistemli şekilde baskı yaratarak bireyi bunaltma, korkutma ve tehdit, bireyin yanızlaştırılarak tecrit edilmesi, onun hakkında söylentiler çıkararak itibara zarar verme, kötü muamele, onu günah keçisi ilan etme, çalışmasında gerekli olan verilere sahip olmasını engelleme şeklinde gerçekleştirilmektedir (Simons, Stark \& DeMarco, 2011; Domínguez Fernández ve ark 2013).

Leymann'a göre mobbing genellikle beş evreden meydana gelir:

Aşama 1: Kritik bir olay, mobbing dinamiklerini harekete geçirir.

Aşama 2: Mobing uygulayıcıları saldırgan eylemlerde bulunurlar ve sürekli agresyon dozlarını arttıtırlar ve mağduru gücü yetmez hale getirirler. Bireyi ötekileştirmek için dedikodu yayma, dışlama gibi eylemleri gerçekleştirirler.

Aşama 3: Bu saldırılar, mağduru iyice sıkıntıya sokuncaya kadar devam eder. Sonunda mağdur yönetimle ilgili şikâyette bulunur. Sıklıkla üst yönetim tarfından bu şikâyet görmezlikten gelinir.

Aşama 4: Bu aşamada, mağdur "zor" veya "zihinsel olarak hasta" olarak damgalanmaktadır. Artık mağdur kendini koruyamayacak duruma gelir. 
Aşama 5: İhraç. Sonunda birey iş yerini terketmeye zorlanır ve mağdur sürekli şikâyet eden hoşnutsuz çalışan olarak damgalanır ( Caporale ve ark 2012; Buunk ve ark 2016 ).

Sağlık çalışanlarının işyerlerinde yaşadıkları psikolojik şiddetin olumsuz çalışma koşulları yarattığı belirlenmiştir. İşyerinde mobbing, çalışanlarda (bireysel boyutta) intihara kadar varan trajik psikolojik rahatsızlıklara neden olabilmektedir. Sağlık sektörü dahil işyeri ortamında mobbing ve tükenmişlik gibi psikolojik sorunlar özellikle çalışanların ruh sağlığını olumsuz yönde etkilemektedir (Teymourzadeh ve ark. 2014). Bir çok ampirik çalışma, psikolojik şiddete maruz kalmış pek çok kurbanın travma sonrası stres bozukluğunu (TSSB) semptomlarını yaşadığı bildirilmiştir. TSB, aşırı stres yaratan veya travmatik bir olaya maruz kalmanın sonucunda ortaya çıkan bir anksiyete bozukluğudur ve psikopatoloji (geriye dönüş yaşantıları, aşırı uyarılma ve kaçınma davranışı) ve tetikleyici etken (yaşamı tehdit edici ve alışılmışın dışında yaşamsal bir olay) bir arada kendini gösterir. Mobing nedeni ile uzun süre sistematik bir biçimde travmaya maruz kalmış kişilerde travmatizasyon süreci bilişsel şemaların veya temel varsayımların parçalanması ile bağlantılıdır. Bireyler kendilerine ve dünyaya biçtikleri anlam gibi iki temel alanda bozulma yaşarlar. Bu temel şematik çarpıtmalar, bu bireylerde güvenlik duygusunun bozulmasına, güç ve kontrol hissinin azalmasına neden olmaktadır. Bu travmatik olay kişinin kendine ve dünyaya yüklediği anlamlarda bozulma meydana gelmesine neden olur ve dünyanın tamamen güvenli bir yer olduğu ve bireyin tamamen yeterli olduğuna dair katı algının bozulmasına ve kişinin de tamamen yetersiz olduğuna dair var olan algının güçlenmesine neden olabilir (Milutinović et al 2009; Signorelli ve ark. 2013, Aksakal ve ark 2015).

Mobing yaşayan mağdur, olayı takıntılı düşünme, tekrarlayan kabuslar, konsantrasyon güçlüğü, uyuşma veya uyanma uyarılma belirtileri, olayı hatırlatan herhangi bir durum ya da davranışlardan kaçınma yaşar. Anhedoni, depresif ruh hali, öfke, düşük benlik saygısı, sindirim sistemi rahatsızlıkları, uyku bozuklukları, anksiyete ve bazen somatizasyon gibi belirtiler tabloya eklenir. İşyerinde mobbing işi ihmal etmeye ve performans azalmasına, iş tatminsizliğinin artmasına, işyerine karşı olumsuz tutum ve davranışlara neden olabilmektedir. Özellikle tekrarlayan travmatik yaşantı kurbanlarda uyumsuz inançların gelişimini ve olaya ilişkin kendi sorumluluklarına yaptıkları atıfları sürekli pekiştirip yoğunlaştırdığını göstermiştir. Bu düşünce yapısı bireyin yeni bir işe başlamasına engel olmakta ve girişimciliğine zarar vermektedir (Dikmetaş ve ark 2011; Şahin ve ark.2012)

Girişimciler birden fazla riskle karşı karşıya kalmaktadırlar. Sayısız aksaklıkla, müşteri/hasta kaybı, ekiple anlaşmazlıklar, artan rekabet, personel sorunlarıyla karşı karşıya gelmektedirler. Her girişim sırasındaki travmatik olaylar ziniciri sağlıklı zihinsel işlevi, güçlü bir benliği sıklıkla test eder. Mobing sıklıkla bu süreçte bireyin bu güçlü yanının ortaya çıkmasına engel olur (Chen ve ark 2009) .

Duffy ve Sperry'ye göre $(2012,172)$, işyerinde mobbing "toplu kayıplar" ile sonuçlanır: iş kaybı, kariyer kaybı, sağlık ve emeklilik kaybı, mesleki itibar kaybı ve yeniden istihdam edilebilirlik, gelir ve finans kaybı, kişisel ve mesleki kimliğin kaybı, aile kaybı, iş ilişkilerinin kaybı, sağlık, geleceğe dair bir güvenlik hissi kaybı, ve adalet ve adalete olan inanç kaybı.

Hastaneler zor çalışma şartları nedeni ile yoğun ve stresli iş ortamlarıdır. Sağlık personeli özellikle hemşireler mobbingin ortaya çıkışıla ilgili ana risk gruplarından biridir. Bunların arasında insan ve maddi kaynakların güvencesizliği, çalışma rutini, vardiya eseri, zorlu çalışma hızı ve az miktarda özerklik gibi konular yer almaktadır. Sağlık sektöründeki işyerlerinde görülen mobbingin sağlık sistemlerinin etkili işleyişine engel olmaktadır (Chen ve ark 2009; Pai, Lee 2011; Karsavuran, Kaya 2015; Alkorashy ve ark 2016).

\section{SONUÇ}

Sonuç olarak mobbing etik dışı bir davranış şeklidir. Sağlık sektörü perspektifinden, insan sağlığının vazgeçilmezliği, toplum sağlığının önemi ve kaynakların etkin ve verimli bir şekilde kullanılmasının gerekliliği üzerine bakıldığında, özellikle sağlık sektöründe çalışan ekibin motivasyonu ve yetkinlik düzeyi önem arz etmektedir. Sağlık personelinin verimli çalışmasını ve girşimciliğini engelleyebilecek mobing şeklindeki olumsuz eylemlerin önüne geçilmesi sadece biryesel sağlık hizmetlerinin değil, toplum sağı̆̆̆ının da gereklilikleri içerisindedir. 


\section{KAYNAKLAR}

Alkorashy HA, Al Moalad FB. (2016) Workplace violence against nursing staff in a Saudi university hospital. Int Nurs Rev. 63(2):226-32.

Aksakal FN, Karaşahin EF, Dikmen AU, Avci E, Ozkan S. (2015) Workplace physical violence, verbal violence, and mobbing experienced by nurses at a university hospital. Turk J Med Sci.

Buunk AP, Franco S, Dijkstra P, Zurriaga R. (2016) Mobbing in Schools and Hospitals in Uruguay: Prevalence and Relation to Loss of Status.J Interpers Violence. Jan 19

Caporale L, Palese A, Bortoluzzi G. (2012) The leadership style as a mitigator of the insurgence of mobbing risk. Results from an empirical research on Italian nurses]. G Ital Med Lav Ergon. Jan-Mar;34

Chen WC, Sun YH, Lan TH, Chiu HJ. (2009) Incidence and risk factors of workplace violence on nursing staffs caring for chronic psychiatric patients in taiwan. Int J Environ Res Public Health. Nov;6(11):2812-21

Chen WC, Hwu HG, Wang JD. (2009) Hospital staff responses to workplace violence in a psychiatric hospital in Taiwan. Int J Occup Environ Health. Apr-Jun;15(2):173-9.

Domínguez Fernández JM, Padilla Segura I (2013). Behavioral types in relation to burnout, mobbing, personality, and adaptation of selfconduct in health care workers. Aten Primaria. Apr;45(4):199-207

Dikmetaş E, Top M, Ergin G (2011). An examination of mobbing and burnout of residents. Turk Psikiyatri Derg. Fall;22(3):137-49

Duffy M, Sperry L. (2007). Workplace mobbing: Individual and family health consequences. The Family Journal, 15(4), 398-404.

Karakaş SA, Okanli A. (2015). The Effect of Assertiveness Training on the Mobbing That Nurses Experience. Workplace Health Saf. Oct;63(10):446-51

Karsavuran S, Kaya S. (2015). The relationship between burnout and mobbing among hospital managers. Nurs Ethics. Sep 8.

Kehribar A, Karabela Ş N, Kart Yaşar K, Okur A,Derya M , Özgür C , Çankaya F (2017). Çalışma hayatında mobbing: nedenleri, bileşenleri ve ülkemizdeki hukuki durumu. Bakırköy Tıp Dergisi;13:1-9

Leymann H. (1990). Mobbing and psychological terror at workplaces, Violence and Victims 5(2), 119-126.

Milutinović D, Prokes B, Gavrilov-Jerkovié V, Filipović D (2009). Mobbing--special reference to the nursing profession. Med Pregl. NovDec;62(11-12):529-33

Pai HC, Lee S. (2011). Risk factors for workplace violence in clinical registered nurses in Taiwan. J Clin Nurs. May;20(9-10):1405-12

Sahin B, Cetin M, Cimen M, Yildiran N. (2012). Assessment of Turkish junior male physicians' exposure to mobbing behavior. Croat Med J. Aug;53(4):357-66.

Sepúlveda-Vildósola AC, Mota-Nova AR, Fajardo-Dolci GE, Reyes-Lagunes LI. (2017). Workplace bullying during specialty training in a pediatric hospital in Mexico: a little-noticed phenomenon. Rev Med Inst Mex Seguro Soc.;55 Suppl 1:S92-S101

Signorelli M S , Costanzo M C , Cinconze M , Concerto C. (2013). What kind of diagnosis in a case of mobbing: post-traumatic stress disorder or adjustment disorder? BMJ Case Rep. bcr2013010080.

Teymourzadeh E, Rashidian A, Arab M, Akbari-Sari A, Hakimzadeh SM. (2014). Nurses exposure to workplace violence in a large teaching hospital in Iran. Int J Health Policy Manag. Oct 4;3(6):301-5

Topa G, Moriano JA. (2013). Stress and nurses' horizontal mobbing: moderating effects of group identity and group support.Nurs Outlook. May-Jun;61(3):e25-31 